\title{
Risky Sexual Behavior and Associated Factors Among High School Students in Gondar City, Northwest Ethiopia
}

\author{
Abebaw Wasie Kasahun ${ }^{1}$, Mezgebu Yitayal ${ }^{2}$, Tadele Girum ${ }^{3}$, Bekri Mohammed ${ }^{4}$ \\ ${ }^{1,3}$ Department of Public Health, College of Medicine and Health Sciences Wolkite University, Ethiopia \\ ${ }^{2,4}$ Institute of Public Health, College of Medicine and Health Sciences, University of Gondar, Ethiopia
}

\section{Article Info}

\section{Article history:}

Received Jun 8, 2017

Revised Aug 11, 2017

Accepted Aug 27, 2017

\section{Keyword:}

Associated factors

High school students

Northwest Ethiopia

Risky sexual behavior

\begin{abstract}
According to World Health Organization (WHO), youth are young people within 15-24 years old. Studies reported that more than half of all new HIV infections occur among people between the ages of 15 and 24 years. Institution based quantitative cross-sectional study was conducted among high school students in Gondar city. Multistage sampling technique was employed to recruit study participants. Data were collected using pretested structured self-administered questionnaire. Data were entered in Epi Info version 7 and analyzed using SPSS version 21. Descriptive statistics were computed to describe important variables in relation to the outcome variable, Binary and multivariable logistic regressions were used to identify independent predictors of the outcome variable. The overall prevalence of risky sexual behavior was $12.8 \%$. Two out of five sexually active respondents ever had unprotected sexual intercourse. Ever used alcohol ((AOR, 3.53 95\% CI (1.73-7.19)), had no parental monitor (AOR, $12.2195 \%$ CI (6.55-22.78), ever watched pornographic film (AOR, 2.24 95\% CI (1.154.35), had no parental discussion on sexual and reproductive health issues (AOR, $2.5795 \%$ CI (1.36-4.85) and peer pressure (AOR, 2.50, 95\%CI (1.205.21 ), were factors which significantly increases the odds of risky sexual behavior among youth. Risky sexual behavior among high school students in Gondar city administration was very high and worrisome; so that collaborated effort is needed from parents, schools, health facilities and health policy makers to bring healthy sexual behavior among school youth.
\end{abstract}

Copyright $@ 2017$ Institute of Advanced Engineering and Science. All rights reserved.

\section{Corresponding Author:}

Abebaw Wasie Kasahun

Department of Public Health, College of Medicine and Health sciences, Wolkite University, Wolkite, Ethiopia email: abebawasie@gmail.com

\section{INTRODUCTION}

According to World health organization (WHO), youth are defined as people belonging to the age group of 15-24 years [1]. The world today is experiencing a rapid increase in the number of young people. One fifth of world population is youth and young adults with more than four fifth in developing countries [2].

Risky sexual behavior is any behavior which increases the probability of negative health consequences associated with sexual contact including Human Immunodeficiency Virus (HIV)/ Acquired Immune Deficiency Syndrome (AIDS) and other Sexually Transmitted Disease (STDs), abortion, unplanned pregnancy and others [3]. However only HIV/AIDS related risky sexual behaviors were investigated in this study. Studies reported that globally more than half of all new HIV infections occur in people between the ages of 15 and 24 years [4],[5]. This health problem is worse in sub-Saharan Africa where condom is hardly used and many young people experience multiple sexual partnership [6]. In Ethiopia youth represent $30 \%$ of the total population, and according to 2009 national antenatal care sentinel surveillance report HIV/AIDS prevalence among youth was $2.6 \%$ [7],[8] which is higher than the general population. High schools are 
institutions where many youth from different elementary schools joined and expand peer network which could affect sexual behavior either positively or negatively. Majority of students enrolled in high school are at mid adolescent level where sexual socialization, experimentation and identity building takes place; So that identifying risky sexual behaviors and associated factors among school youth is crucial to design need based intervention for youth at school.

However previous studies in Ethiopia are concentrated among university and college students, and the existing limited literatures were tailored to examine role of single variable on sexual behavior of youth like parenting practices, peer influence, substance abuse and living arrangement independently in a fragmented way; despite youth are nested in a context where many of the aforementioned factors interact. Furthermore these studies used to define risky sexual behavior in one or two sexual practices but risky sexual behavior is a composite of many sexual practices [9]-[11].

Therefore this study aims to investigate risky sexual behavior and associated factors among high school students in Gondar city, northwest Ethiopia by considering variables in different dimension at a time and using possible sexual practices to measure over all risky sexual behavior.

\section{METHOD}

\subsection{Study design, area and period}

Institution based quantitative cross-sectional study was conducted from March 23 to March 26, 2015 among high school students in Gondar city, northwest Ethiopia. Gondar city (former capital of Ethiopia) is one of the historical and tourist destination place in Ethiopia. It is located 727 Kilometers northwest to Addis Ababa near the Sudanese border. The study was conducted among regular day time $9^{\text {th }}-10^{\text {th }}$ grade students aged 15-24 years during 2015.

\subsection{Sample size}

Sample size was determined using Epi Info version 7 using prevalence of risky sexual behavior and important factors associated with risky sexual behavior. The maximum sample size obtained was by using a factor living arrangement. 95\% confidence interval, $80 \%$ power, risky sexual behavior among students living with biological parent (outcome among unexposed) $16.9 \%$ and living apart from parent (outcome among exposed) $24.6 \%$, odds ratio 2 [12], 1.5 design effect and $10 \%$ non-response rate and the final sample obtained was 686.

\subsection{Sampling techniques}

Multistage sampling technique was employed to recruit study subjects. First four high schools were selected by using simple random sampling technique out of the total thirteen high schools. Then By using proportional to size allocation technique sample size was distributed to the selected four high schools. Finally sections which could accommodate the allocated sample to each school were selected by using lottery method and the whole eligible students in the selected sections were used for data collection.

\subsection{Data collection tool and procedure}

Data was collected using structured self-administered questionnaire. Questionnaire was adopted from youth risk behavior surveillance system (YRBSS) developed by Family health international(FHI) and used by both developed and developing countries including Ethiopia, Ethiopian demographic and health survey questionnaire and from previous literatures on similar topic [2],[11],[13]-[15].The questionnaire was initially developed in English and translated to Amharic(local language) and then back to English by different language experts to check for meaning consistency and it was pretested in similar setting out of the study area using $5 \%$ of the total sample size.

Four MSC students and two BSc nurses were facilitators of data collection, separate places were used for male and female students during data collection. Data collection was completed within one day and similar hour among students in one high school to prevent data contamination.

\subsection{Data analysis and quality management}

Data was cleaned, coded and entered to EPIINFO 7 and then imported to SPSS version 21 for analysis.5\% of the data was double entered to compare and assure the quality of the data. Frequency was computed for all variables and bivariate analysis was made to see association of each independent variable with the outcome variable. And variables with $\mathrm{p}<0.2$ were entered to multivariable logistic regression to identify independent predictors of risky sexual behavior. Hosmer and Lemeshow model fitness test was used to check how data fitted well and it was good with $\mathrm{p}=0.803$. 


\subsection{Measurements}

Risky sexual behavior: defined as practicing either of (unprotected sex, multiple sexual partner with in six month period, having sexual contact with commercial sex workers, or casual sex). Comprehensive Knowledge on HIV/AIDS: assessed using three questions for HIV prevention and five questions regarding local misconception on HIV prevention and transmission methods, respondents who correctly respond three HIV prevention methods and had no any misconceptions regarding its transmission were labeled as knowledgeable while the rest labeled as not knowledgeable.

Parent child communication on sexual issues: respondents were considered to have parental communication if he/she had communication with parents at least once on abstinence, HIV/AIDS or condom in the last 6 months, otherwise labeled as poor communication. Family connectedness: assessed using six items five point Likert scale questionnaire with Cronbach's alpha 0.93.respondents who score above the mean were regarded as had good perceived family connectedness and the rest were regarded as had poor perceived family connectedness.

Parental monitoring: was assessed using three "YES" "NO" questions and respondents who Admit yes at least for one of the three questions were regarded as had parental monitoring while the rest regarded as had no parental monitoring. Multiple sexual partner: respondents reported two and above sexual partner with in six month period before the survey were considered as had multiple sexual partner. High school students: students enrolled in grade $9^{\text {th }}-10^{\text {th }}$ since 2015 .

\subsection{Ethical consideration}

Ethical clearance was obtained from university of Gondar Institutional ethical Review Board with IPH/2293/08/07 reference number, permission was obtained from directors of respective schools and fully informed verbal consent was obtained from the study subjects after explaining the purpose, and objectives of the study.

For students less than 18 years parental consent form had sent to parents through their kids one week prior to data collection and written parental consent was collected through home room teacher for successive five days by reminding students to bring it. At the end respondents' verbal assent was obtained to collect data. Confidentiality of respondents' information was safeguarded as questionnaire was anonymous. Finally information on risky sexual behavior related to HIV/AIDS was given after the data collection was completed.

\section{RESULTS}

Six hundred seventy three respondents return the questionnaire which made response rate $98.1 \%$. Three hundred eight $(45.8 \%)$ respondents were males and the remaining $54.2 \%$ were females. The mean age of respondents was $17.3 \pm 1.6$ years. All demographic characteristics of respondents were summarized in Table 1.

\subsection{Individual risk related behaviors}

Two hundred forty three (36.1\%) of all respondents had ever used alcohol,among these $76.9 \%$ (187) had used alcohol with in thirty days prior to the survey. And 179(26.6\%) of respondents had ever watched pornographic film as illustrated in Table 2 .

\subsection{Comprehensive knowledge of respondents on HIV/AIDS}

Only one hundred seven (15.9\%) of respondents were knowledgeable regarding HIV/AIDS prevention and transmission mechanisms. Two hundred seventy three $(40.6 \%)$ respondents believed mosquito bite can transmit HIV/AIDS and 279(41.5\%) respondents claimed using condom at all sexual intercourse could not help to prevent getting HIV/AIDS as illustrated in Table 3.

\subsection{Parental monitoring}

One hundred twenty (17.8\%) of respondents had no parental monitor and the remaining $82.2 \%$ of respondents had parental monitor. Of all respondents $492(73.1 \%)$ and $444(66 \%)$ of respondents reported as their parents know where they are and with whom they stay when they leave home out of school time respectively. Furthermore, there are 157(51\%) of male respondents and 197(54\%) of female respondents mentioned as their parents forbid them not to play with opposite sex. Family connectedness: of all study subjects 505(75\%) of respondents had good perceived family connectedness while the rest 168(25\%) had poor perceived family connectedness. 
Table 1. Socio-demographic Characteristics of High School Students

\begin{tabular}{|c|c|}
\hline Variables $(\mathrm{N}=673)$ & Frequency (\%) \\
\hline \multicolumn{2}{|l|}{ Sex } \\
\hline Male & $308(45.8)$ \\
\hline Female & $365(54.2)$ \\
\hline \multicolumn{2}{|l|}{ Grade } \\
\hline $9^{\text {th }}$ & $352(52.3)$ \\
\hline $10^{\text {th }}$ & $321(47.7)$ \\
\hline \multicolumn{2}{|l|}{ Age } \\
\hline $15-19$ & $611(90.8)$ \\
\hline $20-24$ & $62(9.2)$ \\
\hline \multicolumn{2}{|l|}{ Ethnicity } \\
\hline Amhara & $638(94.8)$ \\
\hline Tigrie & $23(3.4)$ \\
\hline Others & $12(1.8)$ \\
\hline \multicolumn{2}{|l|}{ Parental residence } \\
\hline Urban & $463(68.8)$ \\
\hline rural & $210(31.2)$ \\
\hline \multicolumn{2}{|l|}{ Marital status } \\
\hline Single & 662(98.4) \\
\hline Others & $11(1.6)$ \\
\hline \multicolumn{2}{|l|}{ Living arrangement } \\
\hline Both biological parent & $405(60.2)$ \\
\hline Mother only & $108(16)$ \\
\hline Father only & 12(1.9) \\
\hline Relatives & $121(18)$ \\
\hline Others & $26(3.9)$ \\
\hline \multicolumn{2}{|l|}{ Father education status } \\
\hline Illiterate & 132(19.6) \\
\hline Can read and write only & 202(30) \\
\hline Primary school completed & $100(14.9)$ \\
\hline Secondary school completed & $87(12.9)$ \\
\hline Above secondary school & $152(22.6)$ \\
\hline \multicolumn{2}{|l|}{ Mother education status } \\
\hline Illiterate & $223(33.2)$ \\
\hline Can read and write only & $184(27.2)$ \\
\hline Primary school completed & $79(11.7)$ \\
\hline Secondary school completed & $123(18.3)$ \\
\hline Above secondary school & $64(9.5)$ \\
\hline
\end{tabular}

Table 2. Individual Risk Related Behaviors among High School Students in Gondar City Adminstration, Northwest Ethiopia

\begin{tabular}{lc}
\multicolumn{1}{c}{ Variables } & Frequency (\%) \\
\hline Ever used alcohol(N=673) & $243(36.1)$ \\
Yes & $430(63.9)$ \\
No & \\
Last month frequency of alcohol use(N=243) & $15(6.2)$ \\
Daily & $117(48.1)$ \\
At least once a week & $55(22.6)$ \\
Less than once a week & $56(23.1)$ \\
Never used since last month & \\
Ever chew khat (N=673) & $37(5.5)$ \\
Yes & $636(94.5)$ \\
No & \\
Last month frequency of chewing khat(N=37) & $2(5.4)$ \\
Daily & $19(51.4)$ \\
At least once a week & $10(27)$ \\
Less than once a week & $6(16.2)$ \\
Never used since last month & \\
Ever watched pornographic film (N=673) & $179(26.6)$ \\
Yes & $494(73.4)$ \\
No & \\
Last month frequency of watching pornographic film(N=179) & $16(8.9)$ \\
Daily & $57(31.8)$ \\
At least once a week & $56(31.3)$ \\
Less than once a week & $50(27.9)$ \\
Never used since last month & \\
\hline
\end{tabular}


Table 3. HIV/AIDS Related Comprehensive Knowledge among High School Students in Gondar City Administration, Northwest Ethiopia

\begin{tabular}{lc}
\hline \multicolumn{1}{c}{ Variables (N=673) } & Frequency \\
\hline Abstinence help not to get HIV/AIDS & \\
Yes & $605(89.9)$ \\
No & $68(10.1)$ \\
Having one faithful sexual partner help to prevent getting HIV/AIDS & $451(67)$ \\
$\quad$ Yes & $222(33)$ \\
No & \\
Using condom at all sexual intercourse help to prevent getting HIV/AIDS & $394(58.5)$ \\
Yes & $279(41.5)$ \\
No & $153(22.7)$ \\
HIV/AIDS patient can be detected by observing body built & $520(77.3)$ \\
Yes & \\
No & $621(92.3)$ \\
HIV can be transmitted through sharing sharp materials & $51(7.7)$ \\
Yes & $616(91.5)$ \\
No & $57(8.5)$ \\
HIV can be transmitted from mother to child & $273(40.6)$ \\
Yes & $400(59.4)$ \\
No & \\
Mosquito bite can transmit HIV/AIDS & $324(48.1)$ \\
Yes & $349(51.9)$ \\
No &
\end{tabular}

\subsection{Parent child communication on sexual and reproductive health issues}

Three hundred seventy two $(55.3 \%)$ respondents had discussed at least once on abstinence, HIV/AIDS or condom in the last six month before the survey as illustrated in Table 4. Peer related factors: Eighty eight (13.1\%) of respondents had perceived they had had peer pressure to have sex and $138(20.5 \%)$ of respondents had sexually active peers.

Table 4. Parent Child Discussion on Sexual and Reproductive Health Issues among

\begin{tabular}{|c|c|}
\hline Variables $(\mathrm{N}=673)$ & Frequency $(\%)$ \\
\hline \multicolumn{2}{|c|}{ Have you ever discussed with parents regarding HIV/AIDS } \\
\hline Yes & 258(38.3) \\
\hline No & $415(61.7)$ \\
\hline \multicolumn{2}{|c|}{ Have you ever discussed on abstinence with parents } \\
\hline Yes & $237(35.2)$ \\
\hline No & $436(64.8)$ \\
\hline \multicolumn{2}{|c|}{ Have you ever discussed on condom use with parents } \\
\hline Yes & $138(20.5)$ \\
\hline No & $535(79.5)$ \\
\hline
\end{tabular}

\subsection{Sexual behavior}

One hundred fifty nine respondents (23.6\%) with (95\% CI 20\%-27\%)) were sexually experienced at the time of survey. Higher proportion of males 93 (54.5\%) were sexually active while 66(45.5\%) females were sexually active. The mean age at first sexual commencement was $15.9 \pm 1.3$ years old, which is $16.2 \pm 1.3$ for males and $15.6 \pm 1.2$ among females. One hundred thirty four $(84.3 \%)$ of sexually active youth were below 18 year at the time of sexual initiation.

Majority of sexually experienced respondents $(81.1 \%)$ ) were also sexually active within 6 months period before the survey. Thirty six $(22.6 \%)$ of sexually active respondents used alcohol during the day they had last sexual intercourse. Eighty two (51.6\%) and $25(15.7 \%)$ of sexually active respondents had had more than one sexual partner in life time and within six month period before the survey respectively.

Thirty one $(19.5 \%)$ of sexually active respondents ever had more than one sexual partner concurrently. Furthermore $16(16.7 \%)$ of all sexually active male respondents had sexual contact with commercial sex workers, among those only $3(18.8 \%)$ of men who had sexual contact with prostitute uses condom in all sexual act with commercial sex workers while the remaining 13(81.2\%) never or often used condom. Twenty nine $(18.2 \%)$ of all sexually active respondents had had history of sexual contact with casual sex partner. 
Two out of five sexually active respondents (40.3\%) ever had unprotected sexual intercourse. On the other hand, there are $111(69.8 \%)$ of sexually active respondents used condom at their most recent sex. Trusting sexual partner was the most frequently mentioned reason for not using condom followed by unavailability of condom and condom will decrease sexual pleasure respectively. Overall prevalence of risky sexual behavior in this study was $12.8 \%$ with $(95 \% \mathrm{CI}, 10.4 \%-15.3 \%)$ ). Of which $62(72.1 \%)$ were males and the rest $24(27.9 \%)$ were females.

\subsection{Factors associated with risky sexual behavior}

In multivariable logistic regression respondents who ever used alcohol (AOR=3.53, 95\% CI, 1.737.19), ever watched pornographic film $(\mathrm{AOR}=2.24,95 \% \mathrm{CI}, 1.15-4.35)$, had no parental monitor $(\mathrm{AOR}=12.21,95 \% \mathrm{CI}, 6.55-22.78)$,ever had peer pressure $(\mathrm{AOR}=2.50,95 \% \mathrm{CI}, 1.20-5.21)$, had parental discussion on $\mathrm{SRH}$ issues $(\mathrm{AOR}=2.57,95 \% \mathrm{CI}, 1.36-4.85)$ were factors significantly associated with risky sexual behavior.

As illustrated in the Table 5 the odds of risky sexual behaviors among respondents ever used alcohol were 3.5 times higher than their counterpart, and the odds of risky sexual behavior among those ever watched pornographic film were 2.2 times higher than their counter part. The odds of practicing risky sexual behavior among respondents who had no parental monitor were 12 times higher than respondents who had parental monitor. Besides the odds of risky sexual behavior among respondents who had no parental discussion regarding sexual and reproductive health issues were 2.6 times higher than their counterpart. Respondents who had experienced peer pressure to have sex were 2.5 times at higher risk to practice risky sexual behavior than their counterpart

Table 5. Factors Associated with Risky Sexual Behavior among High School Students in Gondar City, Northwest Ethiopia

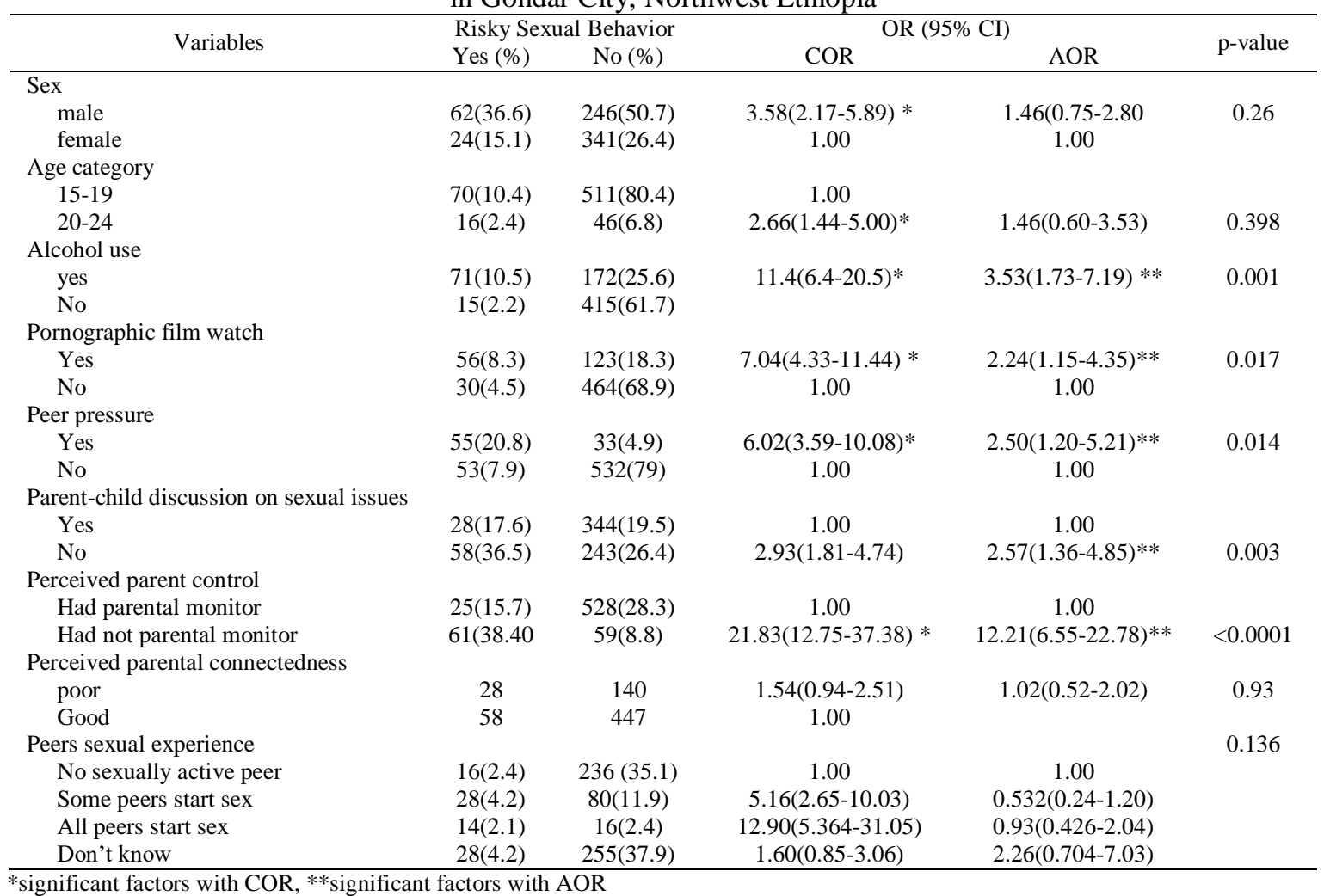

\section{DISCUSSION}

The study assessed prevalence of risky sexual behaviors and associated factors among high school students in Gondar city administration. The overall prevalence of risky sexual behavior in this study was $12.8 \%$ with $((95 \% \mathrm{CI}, 10.4 \%-15.3 \%))$. This finding is in line with findings from Humera high school where $13.7 \%$ with $(95 \% \mathrm{CI}, 10.6 \%-16.8 \%)$ of respondents ever had risky sexual behaviour [16]. This is due to geographical as well as cultural closeness between the two study areas, as a result the population attitude for 
having sex and taking safe measures would be equally affected. However this finding is lower than findings among Bodity high school students in Wolayita at which 17.9\% (CI 14.7\%-21.5\%) respondents had risky sexual behaviour [12]. This could be explained as a result of preparatory school youth were involved besides to $9^{\text {th }}$ and $10^{\text {th }}$ unlike this study, so that higher grade students had more exposure to practice risky sexual behaviors than junior high school students.

The mean age at first sexual commencement in this study was $15.9 \pm 1.3(16.2 \pm 1.3$ and $15.6 \pm 1.2$ among males and females respectively). This demonstrates that high school students are sexually active at an early age which prolongs their exposure to contract sexual ill health including HIV/AIDS. This is nearly similar with mean age at first sexual initiation among Indian urban school adolescents which was 15.25 and 16.66 years old among females and males respectively [17]. This can be explained as a result of the two study areas were urban setting and majority of participants in both studies were in adolescent age category so that their sexual behavior will be closely related. However this finding was lower than the mean age at first sex among Bodity high school students which was $16.6 \pm 2$ equally for male and female youth [12]. This discrepancy could be as a result of age difference between participants. In this study only $9^{\text {th }}$ and $10^{\text {th }}$ grade students were participated at which their age predominates in adolescent age category unlike a study in boditti which includes $11^{\text {th }}$ and $12^{\text {th }}$ besides to $9^{\text {th }}$ and $10^{\text {th }}$ so that older age respondents were more represented and sexually inactive older age respondents may lower overall sexual initiation.

Two out of five sexually active respondents had ever involved in unprotected sexual intercourse at some point in their life. This finding is higher than a finding from national level study in Ethiopia at which only $14.3 \%$ of sexually active respondents reported unprotected sex [10]. This can be explained by large sample size was used in national study which includes both urban and rural setting and the national study was among unmarried youth and most unmarried youth in rural setting in Ethiopia are less likely to be sexually active and hence magnitude of unprotected sex decreases as compared to this finding.

Eighty two $(51.6 \%)$ of sexually active respondents ever had more than one sexual partner. This finding is lower than findings from other parts of Ethiopia (enemay district and Awi zone) [13],[18]. The difference may be as a result of these studies include $11^{\text {th }}-12^{\text {th }}$ grade students besides to $9^{\text {th }}-10^{\text {th }}$ unlike this study which relays on $9^{\text {th }}$ and $10^{\text {th }}$ only, Which may increase a potential to have many sexual partner as they pass from grade to grade.

In this study thirty three $(20.8 \%)$ of sexually active respondents had sexual contact with non-regular sexual partner including commercial sex workers. This finding is lower than findings from Colombia at which $40 \%$ of youth had sexual contact with non-regular sexual partner [19]. This difference could be due to socioeconomic and cultural difference across countries. However this finding is similar with a study in Nigeria [20].

In this study respondents who ever drink alcohol were at higher risk to involve in risky sexual behavior. This is as a result of myopic effect of alcohol to make rational decision by considering the consequence of sexual practices. Individuals with alcohol influence make decision without analyzing consequences to be followed after having sex. This finding is in line with findings from national level study in Ethiopia and northwest Ethiopia [10],[21]. Similarly alcohol is associated with risky sexual behavior in Bolivia and Kenya [22],[23].

Respondents who ever watched pornographic film were at higher risk to involve in risky sexual behavior. This finding is in line with studies in Saudi Arabia and other parts of Ethiopia from Jimma and Humera [16],[24],[25]. This may be due to access of enhanced mobile technology, internet and wide spread porn video media portrayals across every corner of the world which fuels the problem of risky sexual behavior among youth, further more adolescents are sensitive to experiment what they hear and look as a result of natural transition stage to adult and hence they are prone to be driven by porn video they watch to experiment risky sex. However national level study in Ethiopia indicate pornographic film is not associated with sexual behaviour [10]. This is due to national study includes youth from rural areas to represent national youth where internet access and mobile technology are hardly accessed.

Parental monitor is significantly associated with risky sexual behavior at which the odds of engaging in risky sexual behavior among respondents who had no parental monitor were twelve times higher than their counter part. This finding is in line with findings from Salvador Tanzania and other parts of Ethiopia (Harar, west Ethiopia, and Gojam) [9],[26]-[29]. This is due to parental monitoring makes youth to remain abstinent and enables youth to solicit with youth who had no deviant behavior.

Respondents who ever had parental discussion on sexual and reproductive health issues were less likely to involve in risky sexual behaviors. This is supported by other studies in South Africa and other parts of Ethiopia [26],[30]. This could be due to parent child discussion equips youth with skill and information to remain safe towards risky sexual behavior.

Respondents who ever experienced peer pressure to have sex were 2.5 times more at risk to involve in risky sexual behavior than their counter part. This finding is in line with studies in other parts of Ethiopia 
in Bahir Dar, Gojam, and western Ethiopia [26],[27],[31]. This could be due youth spend most of their time with their peers so that peers are most influential socializing agent for sexuality among youth. Besides youth need attention, and recognition with peers so that they are liable to behave in a manner intimate friend practice. This is also supported by studies in South Africa and Cameroon [30],[32].

\section{LIMITATION OF THE STUDY}

As a result of cross-sectional study design is used temporal relationship between outcome and explanatory variables cannot be determined, further more sexual and reproductive health information are sensitive by their nature so that social desirability bias cannot be completely ruled out and the study is limited to school so that the result cannot be generalized to the whole youth in the study area.

\section{CONCLUSIONS AND RECOMMENDATIONS}

Risky sexual behavior among high school students in Gondar city administration was very high and worrisome. Ever used alcohol, ever watched pornographic film, had no parental monitor, had no parent-child discussion on SRH issues, and peer pressure to have sex were factors increased practice of risky sexual behavior among youth in the study area. Considerable proportion of youth had poor knowledge and misconceptions towards HIV/AIDS transmission and prevention methods.

School based sex education need to be incorporated with curriculum and integrated with local health departments so that health professionals would have constant session to disseminate factual information to build knowledge on sexual issues and break misconceptions towards sexual HIV transmission. Better to provide life skill training for selected students from all high schools to be potential trainers in their respective school and provide continuous support and encouragement afterward. Which capacitate students to say no for early sexual intercourse or negotiate for safe sex practice. There is a need to equip parents with appropriate information education communication (IEC) material on communication skill and sexual health issues.

Teachers and school administers better be alert and responsive for any deviant behavior like watching pornographic video in mobile among students. Strength school anti AIDS club members and organize school mini-media to provide information on risky sexual behavior to HIV infection in better way than ever before. Parents need to be unreserved to know every day's activity of their kid from school and out of school including knowing with whom their children stay more.

\section{AUTHOR'S CONTRIBUTION}

AW conceived and carried out all phases of this research work including manuscript writing

MY critically evaluated the design and interpretations of results

$\mathrm{BM}$ collaborated in proposal development and assists in data analysis.

\section{ACKNOWLEDGMENT}

The authors are highly indebted to university of Gondar, institute of public health for financing this research work. We also would like to express our special thanks to Gondar city education bureau and high schools for their genuine cooperation during data collection. Last but not least we would like to acknowledge study participants for their information with full cooperation.

\section{REFERENCES}

[1] WHO, "The health of young people:a challenge and a promise," World health organization, 1995.

[2] Fentahun N. and Mamo A., "Risky sexual behaviors and associated factorsamong male and female students in jimma zone preparatory schools, south west ethiopia:Comparative study," Ethiopian journal of health science, vol/issue: 24(1), 2014.

[3] Cooper M. L., "Alcohol Use and Risky Sexual Behavior among College Students and Youth: Evaluating the Evidence," Journal of studies on alcohol, vol. 14, 2002.

[4] UNFPA, "The state of world population," Geneva, 1997.

[5] Shiferaw K., et al., "Assessment of adolescents' communication on sexual and reproductive health matters with parents and associated factors among secondary and preparatory schools' students in Debremarkos town, North West Ethiopia," Reproductive health journal, vol. 11, 2014.

[6] Chandra M. V., et al., "Contraception for adolescents in low and middle income countries: needs, barriers, and access," Reproductive health journal, vol/issue: 11(1), 2014.

[7] HAPCO, "The second HIV/AIDS Behavioural Surveillance Survey (BSS)," 2005. 
[8] Ethiopian Health and Nutrition Research Institute (EHNRI), "Report on the 2009 Round Antenatal Care Sentinel HIV Surveillance in Ethiopia,” Addis Ababa, 2011.

[9] Dessie Y., et al., "High parental monitoring prevents adolescents from engaging in risky sexual practices in Harar, Ethiopia," Global Health Action, vol/issue: 7(25724), 2014.

[10] Kebede D., et al., "Khat and alcohol use and risky sex behaviour among in-school and out-of-school youth in Ethiopia," BMC, vol/issue: 5(109), 2005.

[11] Abebe M., et al., "Living with parents and risky sexual behaviors among preparatory school students in Jimma zone, South west Ethiopia," African health science, vol/issue: 13(2), 2013.

[12] Daka D., "Magnitude of risk sexual behaviour among high school adolescents in Ethiopia," Journal of public health and epidemiology, vol/issue: 6(7), pp. 211-215, 2014.

[13] Dekeke G. D. and Sandy P. T., "Factors influencing sexual risk behaviour among senior secondary school students," International Journal of Scientific and Research Publications, vol/issue: 4(8), 2014.

[14] EDHS, "Ethiopian Demographic and Health Survey," Addis Ababa, 2011.

[15] Family Health International, "Youth risk behavior surveillance system," 2000.

[16] Dadi A. F. and Teklu F. G., "Risky sexual behavior and associated factors among grade 9-12 students in Humera secondary school, western zone of Tigray, NW Ethiopia," Science Journal of Public Health, vol/issue: 2(5), pp. 410-416, 2014.

[17] Ramadugu S., et al., "Understanding sexuaity among Indian urban school adolescents," Industrial psychiatry journal, vol/issue: 20(1), 2011.

[18] Mekuria M., "Premarital sexual practice and perception of high risk of hiv/aids among school adolescnts in injibara town, awi zone," Addis Ababa, 2008.

[19] Campo A. A., et al., "Prevalence of Pattern of Risky Behaviors for Reproductive and Sexual Health Among Middle- and High-School Students," Rev Latino-Am Enfermagem, vol/issue: 18(2), pp. 170-174, 2010.

[20] Stella C., et al., "Survey of sexual networking in Calabar," Health Transition Review, vol. 3, 1993.

[21] Alemu H., et al., "Factors Predisposing Out-of-School Youths to HIV/AIDS-related Risky Sexual Behaviour in Northwest Ethiopia," J Health Popul Nutr, vol/issue: 3(344), 2007.

[22] Mensch B. S., et al., "Premarital Sex, Schoolgirl Pregnancy, and School Quality in Rural Kenya," Studies in Family Planning, vol/issue: 32(4), 2001.

[23] Novilla M. L. B., et al., "Adolescents Engaging in Risky Sexual Behavior: Sexual Activity and Associated Behavioral Risk Factors in Bolivian Adolescents," International Electronic Journal of Health Education, vol. 9, 2006.

[24] A. M. Gebretsadik, "Family environment and sexual behaviours in Jimma zone, south west Ethiopia," Science journal of public health, vol/issue: 2(6), pp. 539-545, 2014.

[25] Raheel H., et al., "Sexual practices of young educated men: implications for further research and health education in Kingdom of Saudi Arabia (KSA)," Journal of public health, vol/issue: 35(1), pp. 21-26, 2011.

[26] Negeri E. L., "Assessment of risky sexual behaviors and risk perception among youths in Western Ethiopia: the influences of family and peers: a comparative cross-sectional study," BMC, vol/issue: 14(301), 2014.

[27] Asrat A., "Assessment of sexual risk behaviours of in-school youth: Effect of living arrangement of students; West Gojam zone, Amhara regional state, Ethiopia," American Journal of Health Research, vol/issue: 2(2), 2014.

[28] Mlunde L. B., et al., "A call for parental monitoring to improve condom use among secondary school students in Dar es Salaam, Tanzania,” BMC, vol/issue: 12(1061), 2012.

[29] Springer A. E., et al., "A descriptive study of youth risk behavior in urban and rural secondary school students in El Salvador," BMC, vol/issue: 6(3), 2006.

[30] Awotidebe A., et al., "Factors Contributing to the Risk of HIV Infection in Rural School-Going Adolescents," International journal of environmental research and public health, vol. 11, 2014.

[31] Mulugeta Y. and Berhane Y., "Factors associated with pre-marital sexual debut among unmarried high school female students in bahir Dar town, Ethiopia: cross- sectional study," Reproductive health journal, vol/issue: 11(40), 2014.

[32] Meekers D. and Calves A. E., "Gender differential in adolescent sexual activity and reproductive health risks in cameroon," African Journal of Reproductive Health, vol/issue: 3(2), 1999. 